\title{
Impacto da desoneração da folha de pagamento em uma indústria alimentícia
}

\author{
Zilma da Silva \\ Universidade do Estado de Mato Grosso (UNEMAT) \\ Brasil
}

Ex-aluna do curso de Ciências Contábeis, ou seja, Bacharel em Ciências Contábeis.

\begin{abstract}
Vanderléia Aparecida da Silva Guimarães
Especialista em Auditoria e Perícia Contábil, professora do curso de Ciências Contábeis da UNEMAT - Campus de Tangará da Serra

Brasil

Mestranda no Programa de Pós-Graduação em Ciências Contábeis na Fundação Instituto Capixaba de Pesquisas em Contabilidade, Economia e Finanças (FUCAPE).

\section{Nataliê Cristy Guzatti}

Universidade do Estado de Mato Grosso (UNEMAT)

Brasil
\end{abstract}

Mestranda no Programa de Pós-Graduação em Contabilidade na Universidade Federal do Paraná (UFPR).

\author{
Núbbia Mendonça Oliveira \\ Universidade do Estado de Mato Grosso (UNEMAT) \\ Brasil
}

Mestranda no Programa de Pós-Graduação em Contabilidade na Universidade Federal do Paraná (UFPR)

\section{Ana Paula Silva de Andrade}

Servidora efetiva da Universidade do Estado de Mato Grosso (UNEMAT)

Brasil

Mestranda no Programa de Pós-Graduação Interdisciplinar em Ambiente e Sistemas de Produção Agrícola (UNEMAT).

Artigo submetido em: 08/01/2018

Aprovado em: 05/02/2018

\section{RESUMO}

O presente trabalho destaca as mudanças ocorridas nas empresas, através das alterações provocadas com a entrada da Lei $\mathrm{n}^{\mathrm{o}} 12.546$ de 14 de dezembro de 2011, no que se refere à Contribuição Previdenciária Substitutiva, conhecida popularmente por "Desoneração da Folha 
de Pagamento" tratada nos artigos $7^{\circ}$ e $8^{\circ}$. Diante do exposto, a finalidade é a redução da carga tributária incidente sobre a folha de pagamento das empresas. Assim, o objetivo da pesquisa foi apresentar o impacto financeiro ocasionado pela implantação da desoneração da folha de pagamento em uma indústria alimentícia de Tangará da Serra - MT. Foram analisadas as vantagens e desvantagens da nova legislação, através de dados mensais da folha de pagamento e o faturamento anual de 2014 coletados na empresa, efetuando comparativos com a normativa anterior. Para atingir os objetivos, os procedimentos metodológicos utilizados tratam-se de estudo de caso, da pesquisa exploratória e abordagem quantitativa, e para melhor entendimento do assunto, foram abordadas as pesquisas bibliográficas, documental e a legislação. Com os resultados da pesquisa, o cálculo sem desoneração chegase no aglomerado de $\mathrm{R} \$ 3.178 .213,73$, e com a desoneração, esse valor tem uma redução significativa de $\mathrm{R} \$ 1.370 .212,32$, apresentando um impacto financeiro de $\mathrm{R} \$ 1.808 .001,41$ menor a ser recolhido no período pesquisado. Portanto, a desoneração da folha de pagamento trouxe um impacto financeiro positivo, representado uma economia de 56,89\% no INSS Patronal a recolher no ano de 2014.

Palavras-chave: Folha de Pagamento. Contribuição Previdenciária. Carga Tributária.

\section{INTRODUÇÃO}

A desoneração da folha de pagamento consiste na Medida Provisória nº 540L lançada pela Presidente Dilma Rousseff, criado em agosto de 2011, e denominado de "Plano Brasil Maior", cujo principal objetivo pretendido pelo governo é reduzir os impostos incidentes na folha de pagamento, sem diminuir os salários e os direitos dos trabalhadores, e também estimular a contratação de pessoal de determinados setores empresariais e, isentando - as da Contribuição Patronal sobre a folha de salários, sobretudo ampliar as exportações (PINTO; AFONSO; BARROS, 2014).

Com essa Medida Provisória, o governo está extinguindo a atual Contribuição Previdenciária Patronal que incide sobre a folha adotando uma nova Contribuição Previdenciária sobre a Receita Bruta das empresas, ou seja, descontando as devoluções e as receitas de exportações, a substituição da base de cálculo da folha pelo faturamento mensal (TEODORO, 2014).

O intuito da implantação da desoneração da folha de pagamento sobre a receita bruta é favorecer o desenvolvimento em alguns setores da economia, a base de cálculo sobre a Contribuição Previdenciária Patronal (CPP), substituída pela Contribuição Previdenciária sobre a Receita Bruta (CPRB), a carga tributária incidente sobre a atividade industrial no Brasil constitui-se em barreira significativa para o desenvolvimento econômico e social do país, e que afeta diretamente as empresas. Sendo assim, a desoneração da folha de pagamento foi criada através do Plano Brasil Maior para estimular criação de empregos formais, 
aumentar a competitividade da indústria nacional, reduzir a tributação e os custos laborais das instituições (BERTINI; WUNSCH, 2013).

Através da Medida Provisória $n^{\circ}$ 540/2011 convertida na Lei $n^{\circ} 12.546 / 2011$, ficou estabelecido que, a Contribuição Previdenciária Patronal terá aplicações das alíquotas de $1 \%$ e $2 \%$ sobre a receita bruta. Com essa nova medida adotada pelo governo, os setores obrigados a cumprir a lei da desoneração são: o setor de Tecnologia da Informação (TI), setor de Tecnologia da Informação e comunicação (TIC), setor de Call Center (a partir de 01/04/2012), setor de Hoteleiro (a partir de 01/08/2012) e também os setores industriais que fabriquem os produtos citados no anexo I da Lei ${ }^{\circ}$ 12.546/2011 (GOULART, 2012). Desta forma, pergunta-se: Com a implantação da Lei n ${ }^{\circ}$ 12.546/2011, a desoneração da folha trouxe vantagens financeiras para a empresa pesquisada?

Sendo assim, o objetivo geral da pesquisa é apresentar o impacto financeiro ocasionado pela implantação da desoneração da folha de pagamento em uma indústria alimentícia de Tangará da Serra/MT. Desencadeiam-se, os seguintes objetivos específicos que permitirá alcançar o resultado da pesquisa: conceituar a legislação da desoneração da folha de pagamento; evidenciar as vantagens e desvantagens do novo cálculo da contribuição patronal e apresentar o impacto financeiro causado pela implantação da desoneração da folha, ou seja, com ou sem desoneração.

O tema em estudo faz-se relevante para toda a sociedade, pois contribui para o conhecimento e aprendizagem sobre a estrutura tributária brasileira, visto que, são poucas as pesquisas realizadas sobre o tema, podendo este servir como base para estudos e pesquisas futuras. Principalmente sobre a desoneração da folha de pagamento, assunto este bastante discutido atualmente, e que onera diversas empresas, beneficiando-as com esse novo método de cálculo.

Desta forma, a pesquisa justifica-se em razão da existência de vários estudos referentes à desoneração da folha tais como: Impacto da Desoneração da folha de Pagamento: Estudo de Caso em uma Metalúrgica (ECKERT et al., 2013), O Impacto Financeiro e Contábil da Desoneração da Folha de Pagamento em Indústrias Calçadistas (BERTINI; WUNSCH, 2013), Um estudo sobre a Desoneração da Folha de Pagamento (GOULART, 2012), Política pública de fomento, desoneração Tributária (MENDONÇA; MOURA, 2014), Impactos da Desoneração da Folha de Pagamentos no setor de Construção Civil (NASCIMENTO; JUVELLA, 2014), Estudo sobre a Desoneração da Folha de Pagamento com base na Lei n ${ }^{\circ}$ 12.546/2011 (SILVA, 2014), Desoneração da Folha de Pagamento: estudo 
de caso na empresa metalúrgica Aço e Silva (MAZAFERRO, 2013), no entanto este tema será pesquisado e aplicado em uma indústria Alimentícia no município de Tangará da Serra - MT.

\section{REFERENCIAL TEÓRICO}

\subsection{Folha de Pagamento}

A folha de pagamento é um documento trabalhista de emissão obrigatória, preparadas por todas as pessoas jurídicas e equiparadas que tenham funcionários, para fins de fiscalização trabalhista e previdenciária. A empresa é obrigada a elaborar a folha de pagamento informando todas as remunerações e descontos de todos os colaboradores (COSTA; PAIXÃO; AGUIAR, 2015).

Conforme o art. 225 do Decreto $\mathrm{n}^{\circ}$ 3.048, de 06 de maio de 1999:

A empresa é também obrigada a preparar folha de pagamento da remuneração paga, devida ou creditada a todos os segurados a seu serviço, devendo manter, em estabelecimento, uma via da respectiva folha e recibos de pagamento (BRASIL, 1999n).

De acordo com a Lei nº. 8.213/91, da Consolidação da Legislação Previdenciária (CLP), a utilização da folha de pagamento é obrigatória pelo empregador desde que haja funcionário. Independente de como é feita, seja manualmente, ou por processos de pontos mecânicos e eletrônicos, desta forma, contendo todos os proventos mensais dos empregados (BISCAIA et al., 2008). A obrigatoriedade também é instituída pela Consolidação das Leis do Trabalho (CLT), pelo Decreto-Lei $\mathrm{n}^{\circ} .5 .452$ de $1^{\circ}$ de Maio de 1943 (BRASIL, 1991d; 1943i).

Através da contratação surge o vínculo empregatício, ou seja, um conjunto de direitos e obrigações entre empregado e empregador, para o empregador esse vínculo constitui na realização das tarefas das empresas, mas para o empregado, o objetivo é a remuneração. Outro detalhe importante que o autor destaca, é o cálculo da folha, visivelmente parece simples, mas calcular a folha de pagamento requer do profissional, certo conhecimento da legislação trabalhista brasileira, a fim de conhecer as exigências legais (KINCZESKI, 2011).

De acordo com a Lei $\mathrm{n}^{\mathrm{o}} 8.212$, de 24 de julho de 1991, as alíquotas incidentes sobre a folha de pagamento são:

INSS Patronal: 20\% (para empresas não optantes pelo simples nacional);

Risco de Acidente de Trabalho (RAT): $1 \%, 2 \%$ ou $3 \%$ e contribuição adicional, se for o caso, variando conforme o grau de risco, esse percentual e acrescido do Fator Acidentário de Prevenção (FAT), cujo índice varia dentro de um intervalo que inicia em 0,5000 e pode chegar até, 2,000.

Outras Entidades (Terceiros): 5,8\% (geralmente) de contribuição variável destinada a entidades como Serviço Social da Indústria (SESI), Serviço Social do Comércio (SESC) e Serviço Nacional de Aprendizagem Industrial (SENAI) entre outras. Esta contribuição é arrecadada junto ao Instituto Nacional do Seguro Social (INSS) e posteriormente repassar (BRASIL, 1991c). 
Com o novo método de cálculo, o maior objetivo da desoneração é a substituição parcial do INSS Patronal sobre a folha de pagamento de salários por uma tributação mensal sobre o faturamento das empresas. Ainda, sendo uma forma de diminuição dos gastos com o quadro funcional e suprir o déficit na arrecadação com o aumento dos impostos calculados com base no faturamento das organizações (SILVA, 2014).

Vale ressaltar, que os encargos sociais sobre as folhas de pagamentos cobrados de empregados incluem os encargos sociais previdenciários, e os impostos federais e estaduais de seguro desemprego. Sendo assim, os empregadores precisam declarar e pagar os impostos para as agências do governo credenciadas, ou seja, deixar de apresentar as declarações exigidas ou de pagar os impostos devidos, os mesmos estão sujeitos a penalidades cíveis, e em alguns casos criminais (VANDERBECK; NAGY, 2001).

\subsection{Contribuição Previdenciária}

Em 1888, surge à primeira legislação especifica sobre Direito Previdenciário, através do Decreto $\mathrm{n}^{\circ} .9 .912$ de 26 de março de 1888p, que regulou o direito a aposentadoria dos empregados dos correios. Em novembro do mesmo ano, surgiu outra norma, a criação da Caixa de Socorros em cada uma das estradas de ferro do Império. Em seguida, no ano de 1892, foi instituída a aposentadoria por invalidez e a pensão por morte aos operários do Arsenal da Marinha, levando em conta que estava vigorando o regime republicano, sob forte influência de cafeicultores e militares. Em 1919, o Decreto Legislativo $\mathrm{n}^{\circ}$. 3.724 o que instituiu obrigatoriamente o seguro por acidente de trabalho, que já vinha sendo praticado por alguns seguimentos, contudo sem previsão expressa na Lei (HOMCI, 2009).

O Direito Brasileiro diz que, embora houvesse no reinado a previsão de contribuição direta, e que a legislação recaia sobre pensão por morte, apenas na república com a Constituição de 1934 que surge a contribuição do empregador confirmada pela Constituição de 1967. E, sendo ampliado através da Emenda Constitucional n ${ }^{\circ} 01$ de 1969, que previu a competência da União para estabelecer outras contribuições para custeamento de encargos da seguridade social (MENDONÇA; MOURA, 2014).

A carta Magna de 1934 foi a primeira a estabelecer o custeio triplicado da Previdência Social, com a participação do Estado, dos empregados e dos empregadores.

Art. 121 - A Lei Promovera o amparo da produção e estabelecera as condições do Trabalho, na cidade e nos campos, tendo em vista a proteção social do trabalhador e os interesses econômicos do País.

$\S 1^{\circ}$ - A legislação do trabalho observará os seguintes preceitos, além de outros que colimem melhorar as condições do trabalhador: (...) (BRASIL, 1934b).

Em 1966, com a alteração de dispositivos da Lei Orgânica da Previdência Social, foram instituídos o Fundo de Garantia por Tempo de Serviço (FGTS). Com essas mudanças o empregador deve recolher ao FGTS $8 \%$ de remuneração mensal do empregado, em conta deste, na Caixa 
econômica Federal (FABRETTI, 1998). O Instituto Nacional de Previdência Social (INPS), atualmente a sigla é (INSS), que reuniu os seis institutos de aposentadorias e pensões existentes, unificando oficialmente a Previdência Social no Brasil. Contudo, o empregador desconta dos funcionários e posteriormente repassa, ou recolhe para o Instituto Nacional de Seguro Social (INSS), portanto, a empresa é apenas depositaria temporariamente desse desconto; ela e responsável pelo cálculo do valor a ser descontado; e b) recolhimento das contribuições ao INSS, no prazo fixado (OLIVEIRA et al., 2003).

Conforme art. 22 da Lei, 8.212/91:

Vinte por cento sobre o total das remunerações pagas, devidas ou creditadas a qualquer título, durante o mês, aos segurados empregados e trabalhadores avulsos que lhe prestem serviços, destinados a retribuir o trabalho, qualquer que seja a sua forma, inclusive as gorjetas, os ganhos habituais sob a forma de utilidades e os adiantamentos decorrentes de reajustes salariais, quer pelos serviços efetivamente prestados, quer pelo tempo a disposição de empregador ou tomador dos serviços, nos termos da lei ou do contrato ou, ainda, de convenção ou acordo coletivo de trabalho ou sentença normativa (BRASIL, 1991c).

Destacada no Art. $1^{\circ}$, da Lei $\mathrm{n}^{\circ} 8.213$ dezembro de 1991, a Previdência Social mediante contribuição, tem por finalidade assegurar aos seus beneficiários, meios indispensáveis de manutenção, por motivo de incapacidade, desemprego involuntário, idade avançada, tempo de serviço, encargos familiares e prisão ou morte daqueles de quem dependiam economicamente (BRASIL, 1991d).

De acordo com Art. 194 da Constituição Federal de 1988, “A seguridade social compreende um conjunto integrado de ações de iniciativa dos poderes públicos e da sociedade, destinadas a assegurar os direitos relativos a saúde, a previdência e a assistência social" coordenado pelo Ministério da Previdência Social (MPS) e como executor de suas políticas o INSS, a Contribuição Previdenciária é recolhida de todos os trabalhadores formais, diretamente ou por meio de seus empregadores para o Fundo de Previdência (BRASIL, 1988a).

A Constituição Federal de 1988, em seu art. 195, determina que:

A seguridade social será financiada por toda a sociedade, de forma direta e indireta, nos termos da lei, mediante recursos provenientes dos orçamentos da União, dos Estados, do Distrito Federal e dos Municípios, e das seguintes contribuições sociais. I - do empregador, da empresa e da entidade a ela equiparada na forma da lei, incidente sobre: (Redação dada pela Emenda Constitucional n 20, de 1998).

a) a folha de salários e demais rendimentos do trabalho pagos ou creditados, a qualquer título, a pessoa física que lhe preste serviço, mesmo sem vínculo empregatício;

b) a receita ou o faturamento;

c) o lucro.

A substituição da folha de pagamento pela receita bruta aplica-se, somente a contribuição patronal paga pelas empresas, equivalente a $20 \%$ de suas folhas salariais mensais, as demais 
contribuições incidentes sobre a folha de pagamento, como FGTS e a contribuição dos próprios empregados para o Regime Geral da Previdência Social, permanecerão inalteradas. Desta forma as empresas que forem abrangidas pela mudança, continuarão recolhendo a contribuição normal (como risco de acidente de trabalho, salário-educação, FGTS e sistema S), apenas a contribuição patronal deixará de ser calculada sobre a folha de salários, e passa a ser calculada sobre a receita bruta (MODENA et al., 2013).

\subsection{Desoneração da Folha de Pagamento}

A Lei 12.546 de 14 de dezembro de 2011, resultado da conversão da Medida Provisória nº 540 do mesmo ano que, substitui o recolhimento da Contribuição Previdenciária Patronal de $20 \%$ sobre a folha de pagamento por uma Contribuição Previdenciária sobre Receita Bruta, variando de $1 \%$ a $2 \%$ para determinados segmentos da economia que já beneficia grandes empresas que se enquadram nos requisitos legais.

Conforme a Lei 12.546/2011:

Art. $7^{\circ}$ Contribuição sobre o valor da receita bruta, excluídas as vendas canceladas e os descontos incondicionais concedidos, em substituição as contribuições previstas nos incisos I e III do caput do art. 22 da Lei $n^{\circ} 8.212$, de 24 de julho de 1991, a alíquota de $2 \%$ (dois por cento): (redação dada pela Lei no 13.043, de 2014).

art. $8^{\circ}$ Contribuição sobre o valor da receita bruta, excluídas as vendas canceladas e os descontos incondicionais concedidos, a alíquota de $1 \%$ (um por cento), em substituição as contribuições previstas nos incisos I e III Lei n 8.212, de 24 de julho de 1991, as empresas que fabricam os produtos classificados na Tipi, aprovada pelo Decreto $\mathrm{n}^{\mathrm{o}} 7.660$, de 23 de dezembro de 2011, nos códigos referidos no anexo I (BRASIL, 2011e).

Esta edição contempla as alterações trazidas pelas Leis 12.715/2012, 12.794/2013 e 12.844/2013 que altera o cálculo da Contribuição Previdenciária Patronal, através da redução da alíquota. Esse novo cálculo sobre a receita bruta viabiliza a redução da contribuição patronal devida pelas empresas e consequentemente a queda da arrecadação nas contas da previdência social. Esta mudança de base, da folha pela receita bruta, incide apenas na contribuição patronal do INSS, e seu recolhimento é feito através de Documentos de Arrecadação de Receitas Federais (DARF) com vencimento até o dia 20 do mês subsequente, antecipando em caso de não ser dia útil (BRASIL, 2012f; 2013g; 2013h).

As demais contribuições que incide sobre a folha de pagamento como o INSS descontados do empregado, a contribuição para outras entidades como: Salário Educação, Serviço Social da Indústria (SESI), Serviço Nacional de Aprendizagem Industrial (SENAI), Serviço Nacional de Aprendizagem do Comercio (SENAC), Serviço Brasileiro de Apoio às Micro e Pequenas Empresas (SEBRAE), Serviço Social do Comércio (SESC), Risco Acidente de Trabalho (RAT), Seguro Acidente de 
Trabalho (SAT) e o Fundo de Garantia por Tempo de Serviço (FGTS), permanece sem alterações (ECKERT et al., 2013).

A desoneração foi constituída com duas medidas complementares, primeiramente para substituir parcialmente a Contribuição Previdenciária Patronal sobre a folha, e assim foi adotada uma nova Contribuição Previdenciária sobre a Receita Bruta desconsiderando as receitas de exportação. A segunda medida foi à mudança da base de contribuição, que pode favorecer na redução da carga tributária do setor beneficiado, ou seja, com uma alíquota fixada em um patamar inferior à alíquota inalterada a arrecadação chamada alíquota neutra (MAZZAFERO, 2013).

Portanto, as empresas que se sentirem prejudicadas poderão ser beneficiadas pela Medida Provisória 669 publicada em 27 de fevereiro de 2015, que faculta às empresas optar pelo recolhimento sobre a receita bruta ou pelo método anterior, ou seja, $20 \%$ sobre a folha de pagamento normal. Para os 56 setores beneficiados pela legislação da desoneração da folha, com a elevação a mais de o dobro das alíquotas vigentes, o governo está forçando a opção dos contribuintes pelo retorno a tributação sobre a folha de pagamento. Somente as empresas com despesa de salários mais elevada em relação à receita será vantajoso permanecer no regime substitutivo (MEDIDA PROVISORIA Nº 669, 2015m).

\subsubsection{Vantagens da Desoneração da Folha}

A principal razão para a adoção dessa alteração tributária é reduzir os custos de produção no Brasil, em especial o custo da indústria, que tem enfrentado dificuldades para competir com os concorrentes internacionais. Como é conhecida, a carga tributária no Brasil é bastante elevada. Por outro lado, a indústria brasileira exporta embutindo em seus preços os altos custos tributários do país, seus concorrentes podem oferecer preços menores, pois pagam menos impostos em seus países de origem (PELLEGRINI; MENDES, 2014).

Sendo assim, são múltiplos os objetivos da folha: Em primeiro lugar, amplia a competitividade da indústria nacional, por meio da redução dos custos laborais, e estimula as exportações, isentando-as da Contribuição Previdenciárias. Em segundo lugar, estimula ainda mais a formalização do mercado de trabalho, uma vez que a Contribuição Previdenciária dependera da receita e não mais da folha de salários. Em terceiro lugar, reduz assimetrias na tributação entre o produto nacional e importado, impondo sobre este último um adicional sobre a alíquota de confins-importação igual à alíquota sobre a receita bruta que a produção nacional pagará para a Previdência Social (MINISTERIO DA FAZENDA, 2012j).

Outro fator interessante a ressaltar, é que se a empresa está operando com o nível máximo de mão de obra e faturamento, pagará mais impostos, entretanto se a mesma estiver operando em nível mais baixo e com um faturamento menor, sua contribuição também será menor, o que gera um equilíbrio para empresa (NASCIMENTO; JUVELLA, 2014). 


\subsubsection{Desvantagens da Desoneração da Folha}

As desvantagens para os setores beneficiados com a desoneração, é que em certos casos individuais, pode acarretar em agravamento da carga tributária, é o caso dos contribuintes cuja sua proporção da folha de pagamento é muito menor do que a receita bruta, e não terão a opção de permanecer no regime anterior. Entretanto, a medida adotada da desoneração setorial, além de não garantir como foi visto, no aumento dos postos de trabalho e a formalização das relações de trabalho, pode acabar comprometendo a Previdência Social Pública, e com isso acarretando um desequilíbrio financeiro e atuarial do Regime Geral da Previdência Social, tornando mais vulnerável, havendo um verdadeiro retrocesso violador dos direitos sociais (MENDONÇA; MOURA, 2014).

Vale ressaltar, que uma das maiores preocupações é que pode caracterizar uma desvantagem, e está voltada ao fato, de que essa nova forma de contribuição venha a diminuir a arrecadação da Previdência Social, uma vez que terá uma diminuição bastante considerável nos valores arrecadados, visto que, há aqueles que se atentam com o custeio futuro, que a Previdência fornece no sentido de proteger os beneficiários do INSS, como por exemplo: os aposentados e os segurados em geral (NASCIMENTO; JUVELLA, 2014).

\section{METODOLOGIA}

O estudo classifica-se como pesquisa exploratória. A caracterização do estudo como pesquisa exploratória normalmente ocorre quando há pouco conhecimento sobre a temática a ser abordada. Por meio do estudo exploratório, busca-se conhecer com maior profundidade o assunto de modo a torna-lo mais claro ou construir questões importantes para a condução da pesquisa (BEUREN et al., 2004).

O método quantitativo, como o próprio nome indica caracteriza-se pelo emprego da qualificação tanto como nas modalidades de coleta de informações, quanto no tratamento delas por meio de técnicas estatísticas, desde as mais simples, como percentual, média desvio padrão, a mais complexa, como coeficiente de correlação, análise de regressão etc. Ainda destaca que, em termos gerais, a análise documental consiste em uma série de operações que visam estudar a analisar um ou vários documentos para descobrir as circunstancias sociais e econômicas com as quais podem estar relacionadas (RICHARDSON, 2012).

E para melhor entendimento do assunto abordado, foi realizado além do estudo de caso, pesquisas bibliográficas, documental e legislação, onde se encontra diversas referências do estudo em questão. Como método de pesquisa, o estudo de caso foi usado em muitas situações, para contribuir ao nosso conhecimento dos fenômenos individuais, grupais, organizacionais, sociais, políticos e relacionados (YIN, 2010). A utilização da pesquisa documental no sentido de organizar informações que se encontram dispersas, servindo como consulta para futuros estudos (BEUREN et al., 2004). 
Apresenta-se como base do estudo uma empresa denominada como "Indústria Alfa", a pedido da mesma, mantendo total sigilo de sua razão social e do seu nome fantasia. Esta indústria foi constituída em 02 de agosto de 1991, onde a mesma atua há 23 (vinte e três) anos na atividade de indústria alimentícia. A indústria "Alfa" é optante pelo regime de tributação do Lucro Real e localizada no município de Tangará da Serra - MT. Portanto, foram demonstrados os cálculos da Contribuição Previdenciária Patronal, com e sem a desoneração da folha de pagamento, evidenciando o impacto financeiro ocasionado pela Lei 12.546/2011, e apresentado esses resultados através de gráfico e tabelas. A pesquisa ocorreu nos períodos de janeiro a dezembro de 2014, por meio dos documentos coletados na empresa, sendo relatórios da folha de pagamentos e faturamento mensais do ano de 2014.

\section{ANÁLISE E DISCUSSÃO DOS RESULTADOS}

Conforme demonstrado na Tabela 1, a empresa pagaria de INSS referente ao mês de janeiro/2014 R \$ 326.203,65. Portanto, se for calculado utilizando o benefício da desoneração da folha aplica-se à alíquota de $1 \%$ sobre a base de cálculo do faturamento bruto, a mesma pagaria de INSS R\$ 217.945,78, referente a janeiro/2014. Foram comparados os períodos com e sem desoneração, conforme o exemplo a seguir.

Tabela 1- Cálculo do INSS patronal com e sem a desoneração da folha de pagamento.

\begin{tabular}{llllccc}
\hline Mês/Ano & Base de cálculo & Valores (R\$) & Alíquota & Terceiros & RAT/FAP & INSS a pagar \\
\hline Jan/2014 & Folha de pagamento & $1.072 .685,47$ & $20 \%$ & $6 \%$ & $4,4136 \%$ & 326.203 .65 \\
Jan/2014 & Receita bruta & $10.627 .921,94$ & $1 \%$ & $6 \%$ & $4,4136 \%$ & $217.945,78$
\end{tabular}

Fonte: elaborado pela autora.

No entanto, o exemplo da Tabela 1, está claro o aspecto positivo da desoneração da folha, pois a empresa teve uma economia de R $\$ 108.257,87$, de INSS a recolher sobre a folha de pagamento de janeiro/2014, esta vantagem financeira poderá ser revertido em novos investimentos na própria empresa.

\subsection{Levantamento do INSS Patronal Sem Desoneração}

Para comparar a real aplicabilidade do INSS patronal e a sistemática da desoneração da folha de pagamento, foi utilizado o faturamento mensal da indústria alimentícia "Alfa", e elaborado um demonstrativo do cálculo demonstrados em gráfico e tabelas, para evidenciar o INSS patronal devido pela empresa. Para a elaboração da tabela com os respectivos valores, foram utilizados os dados mensais do ano de 2014, fornecido pela empresa.

Desta forma, foi aplicada uma alíquota de $20 \%$ sobre a folha de pagamento parte empresa, e consequentemente, foram calculadas as contribuições a terceiros (Alíquota 5,80\%) e outras entidades $(0,20 \%)$, totalizando $6 \%$ sobre a folha de pagamento. Sobre esta folha, incide também o Risco de 
Acidente do Trabalho (RAT) com alíquota de 3\%, mais o Fator Acidentário de Prevenção (FAP) com alíquota de $1.41 \%$, totalizando um percentual de $30,4136 \%$ sobre a folha de pagamento, conforme a Tabela 2.

Tabela 2 - Demonstrativo do cálculo do INSS Patronal sem desoneração da folha de Pagamento.

\begin{tabular}{|cccccc}
\hline Período & Folha de Pagamento & $\begin{array}{c}\text { INSS Patronal } \\
\text { calculado }(\mathbf{2 0} \%)\end{array}$ & Terceiros & RAT/FAP & $\begin{array}{c}\text { Valor a ser pago } \\
\text { em GPS }\end{array}$ \\
\hline Jan/14 & $1.072 .685,47$ & $214.537,09$ & $64.361,13$ & $47.305,43$ & $326.203,65$ \\
\hline Fev/14 & $1.120 .681,32$ & $224.136,26$ & $67.240,88$ & $49.422,05$ & $340.799,19$ \\
\hline Mar/14 & $1.601 .825,11$ & $320.365,02$ & $96.109,51$ & $70.640,49$ & $487.115,02$ \\
\hline Abr/14 & $1.542 .371,89$ & $308.474,38$ & $92.542,31$ & $68.018,60$ & $469.035,29$ \\
\hline Mai/14 & $1.332 .267,66$ & $266.453,53$ & $79.936,06$ & $58.753,00$ & $405.142,60$ \\
\hline Jun/14 & $1.271 .764,70$ & $254.352,94$ & $76.305,88$ & $56.084,82$ & $386.743,65$ \\
\hline Jul/14 & $1.236 .832,04$ & $247.366,41$ & $74.209,92$ & $54.544,29$ & $376.120,62$ \\
\hline Ago/14 & $1.373 .972,77$ & $274.794,55$ & $82.438,37$ & $60.592,20$ & $417.825,12$ \\
\hline Set/14 & $1.259 .298,91$ & $251.859,78$ & $75.557,93$ & $55.535,08$ & $382.952,80$ \\
\hline Out/14 & $1.334 .081,93$ & $266.816,39$ & $80.044,92$ & $58.833,01$ & $405.694,31$ \\
\hline Nov/14 & $1.402 .903,54$ & $280.580,71$ & $84.174,21$ & $61.868,05$ & $426.622,97$ \\
\hline Dez/14 & $1.342 .383,33$ & $268.476,67$ & $80.543,00$ & $59.199,10$ & $408.218,77$ \\
\hline Total & $\mathbf{1 5 . 8 9 1 . 0 6 8 , 6 7}$ & $\mathbf{3 . 1 7 8 . 2 1 3 , 7 3}$ & $\mathbf{9 5 3 . 4 6 4 , 1 2}$ & $\mathbf{7 0 0 . 7 9 6 , 1 3}$ & $\mathbf{4 . 8 3 2 . 4 7 3 , 9 8}$ \\
\hline Fonte: & & & & \\
\hline
\end{tabular}

Fonte: Dados da pesquisa.

Portanto, o estudo sobre a desoneração da folha de pagamento retrata-se, o novo método de cálculo de INSS sobre a Receita Bruta, modificando a forma de contribuição do INSS Patronal, sendo as novas regras imposta pelo governo federal. Desta forma, com o novo cálculo, a área fiscal tem o compromisso de informar o faturamento em tempo hábil para o departamento de pessoal, assim concluindo o fechamento da folha de pagamento com desoneração, encaminhando-se aos gestores as guias de GPS e DARF, antes do vencimento, ou seja, vencendo todo dia 20 de cada mês (SILVA, 2014).

\subsection{Levantamentos do INSS Patronal Com Desoneração}

A Tabela 3 evidencia os cálculos do INSS Patronal, que após a obrigatoriedade da desoneração da folha, conforme o artigo $7^{\circ}$ da Lei 12.546/2011 passa a ser obrigada a recolher $1 \%$ sobre a sua receita bruta.

Tabela 3 - Demonstrativo do cálculo do INSS Patronal com Desoneração (1\% sobre faturamento). 


\begin{tabular}{cccccc}
\hline Período & Receita Bruta & Calculado $(\mathbf{1 \%})$ & $\mathbf{6 \%}$ & $\mathbf{4 , 4 1 3 6 \%}$ & $\begin{array}{c}\text { Valor a ser pago } \\
\text { em GPS }\end{array}$ \\
\hline Jan/14 & $10.627 .921,94$ & $106.279,22$ & $64.361,13$ & $47.305,43$ & $217.945,78$ \\
\hline Fev/14 & $10.611 .360,43$ & $106.113,60$ & $67.240,88$ & $49.422,05$ & $222.776,53$ \\
\hline Mar/14 & $10.676 .567,20$ & $106.765,67$ & $96.109,51$ & $70.640,49$ & $273.515,67$ \\
\hline Abr/14 & $12.336 .154,35$ & $123.361,54$ & $92.542,31$ & $68.018,60$ & $283.922,46$ \\
\hline Mai/14 & $11.667 .474,06$ & $116.674,74$ & $79.936,06$ & $58.753,00$ & $255.363,80$ \\
\hline Jun/14 & $9.497 .923,61$ & $94.979,24$ & $76.305,88$ & $56.084,82$ & $227.369,94$ \\
\hline Jul/14 & $11.546 .950,62$ & $115.469,51$ & $74.209,92$ & $54.544,29$ & $244.223,72$ \\
\hline Ago/14 & $12.382 .310,93$ & $123.823,11$ & $82.438,37$ & $60.592,20$ & $266.853,67$ \\
\hline Set/14 & $13.607 .888,33$ & $136.078,88$ & $75.557,93$ & $55.535,08$ & $267.171,90$ \\
\hline Out/14 & $13.534 .780,17$ & $135.347,80$ & $80.044,92$ & $58.833,01$ & $274.225,73$ \\
\hline Nov/14 & $9.669 .713,15$ & $96.697,13$ & $84.174,21$ & $61.868,05$ & $242.739,39$ \\
\hline Dez/14 & $10.862 .187,78$ & $108.621,88$ & $80.543,00$ & $59.199,10$ & $248.363,98$ \\
\hline Total & $\mathbf{1 3 7 . 0 2 1 . 2 3 2 , 5 7}$ & $\mathbf{1 . 3 7 0 . 2 1 2 , 3 2}$ & $\mathbf{9 5 3 . 4 6 4 , 1 2}$ & $\mathbf{7 0 0 . 7 9 6 , 1 3}$ & $\mathbf{3 . 0 2 4 . 4 7 2 , 5 7}$ \\
\hline
\end{tabular}

Fonte: Dados da pesquisa.

De acordo, com estudo realizado por Bertini e Wunsch (2013), confirma-se o resultado obtido nesta pesquisa, que tanto o impacto financeiro quanto contábil foi positivo após a implementação da desoneração. Segundo os autores, para algumas empresas a desoneração da folha de pagamento, ainda se apresenta uma redução insuficiente da carga tributária, uma vez que os custos trabalhistas continuam pesando financeiramente para as organizações necessitando ainda, de mais medidas de redução a serem adotadas pelo Governo Federal.

Por outro lado, Goulart (2012), orienta com o resultado do estudo, que é necessário ter cautela e planejamento, pois para alguns setores essa desoneração não foi vantajosa (Empresas de confecções e Tecnologia da Informação -TI), por possuir pouca mão de obra em determinados períodos, e em alguns casos o benefício se transforma em custo ainda maior. Sendo assim, essa política de beneficiar alguns segmentos e outros não, de certa forma traz insegurança ao contribuinte que se veem perdido com as constantes alterações na legislação tributária brasileira.

\subsubsection{Comparativo da Contribuição da Empresa}

$\mathrm{Na}$ Tabela 4 foram evidenciando de forma comparativa os dois critérios estudados, no período de janeiro a dezembro de 2014 . 
Tabela 4 - Comparativo do cálculo do INSS Patronal Faturamento X Desoneração da Folha.

\begin{tabular}{ccccc}
\hline & $\begin{array}{c}\text { INSS sobre Folha de } \\
\text { Pagamento (20\%) }\end{array}$ & $\begin{array}{c}\text { INSS sobre Receita } \\
\text { Bruta (1\%) }\end{array}$ & Diferença & $\begin{array}{c}\text { Diferença } \\
\text { financeira \% }\end{array}$ \\
\hline Jan/14 & $214.537,09$ & $106.279,22$ & $108.257,87$ & 50,46 \\
\hline Fev/14 & $224.136,26$ & $106.113,60$ & $118.022,66$ & 52,66 \\
\hline Mar/14 & $320.365,02$ & $106.765,67$ & $213.599,35$ & 66,67 \\
\hline Abr/14 & $308.474,38$ & $123.361,54$ & $185.112,83$ & 60,01 \\
\hline Mai/14 & $266.453,53$ & $116.674,74$ & $149.778,79$ & 56,21 \\
\hline Jun/14 & $254.352,94$ & $94.979,24$ & $159.373,70$ & 62,66 \\
\hline Jul/14 & $247.366,41$ & $115.469,51$ & $131.896,90$ & 53,32 \\
\hline Ago/14 & $274.794,55$ & $123.823,11$ & $150.971,44$ & 54,94 \\
\hline Set/14 & $251.859,78$ & $136.078,88$ & $115.780,90$ & 45,97 \\
\hline Out/14 & $266.816,39$ & $135.347,80$ & $131.468,58$ & 49,27 \\
\hline Nov/14 & $280.580,71$ & $96.697,13$ & $183.883,58$ & 65,54 \\
\hline Dez/14 & $268.476,67$ & $108.621,88$ & $159.854,79$ & 59,54 \\
\hline Total & $\mathbf{3 . 1 7 8 . 2 1 3 , 7 3}$ & $\mathbf{1 . 3 7 0 . 2 1 2 , 3 2}$ & $\mathbf{5 6 , 8 9}$ \\
\hline
\end{tabular}

Fonte: Dados da pesquisa.

Para evidenciar se a desoneração da folha foi vantajosa para a empresa, faz-se necessário a comparação dos dois métodos de cálculos utilizados na pesquisa. Pela Contribuição Previdenciária sobre a folha de pagamento que se encontrava em vigor antes da desoneração, considerando a alíquota de $20 \%$ sobre a folha de pagamento (Tabela 2), e pela receita bruta da empresa (Tabela 3), com a alíquota de $1 \%$ após a obrigatoriedade da Lei $12.546 / 2011$.

Portanto, pode-se observar na Tabela 4, que houve redução no INSS Patronal devido pela empresa "Alfa" no período estudado. Observa-se que a média mensal dos valores sem desoneração ficou em R $\$ 264.851,14$, e com a desoneração, a média do INSS Patronal ficou em $\mathrm{R} \$ 114.184,36$, tendo uma diferença positiva de $\mathrm{R} \$ 150.666,78$ ao mês.

Na tabela 4 apresentam-se, os seguintes resultados apurados no ano de 2014 , ou seja, o cálculo sem desoneração chega ao aglomerado de R \$ 3.178.213,73, e com a desoneração, esse valor tem uma redução significativa de $\mathrm{R} \$ 1.370 .212,32$, apresentando um impacto financeiro de $\mathrm{R} \$ 1.808 .001,41$ menor a ser recolhido no período pesquisado, gerando assim, economia de 56,89\% de INSS Patronal a recolher sobre a folha de pagamento no período de janeiro á 
dezembro de 2014, percentual este bastante expressivo que pode resultar em nova contratação de mão de obra ou talvez outros investimentos.

Gráfico 1 - Comparativo INSS Patronal.

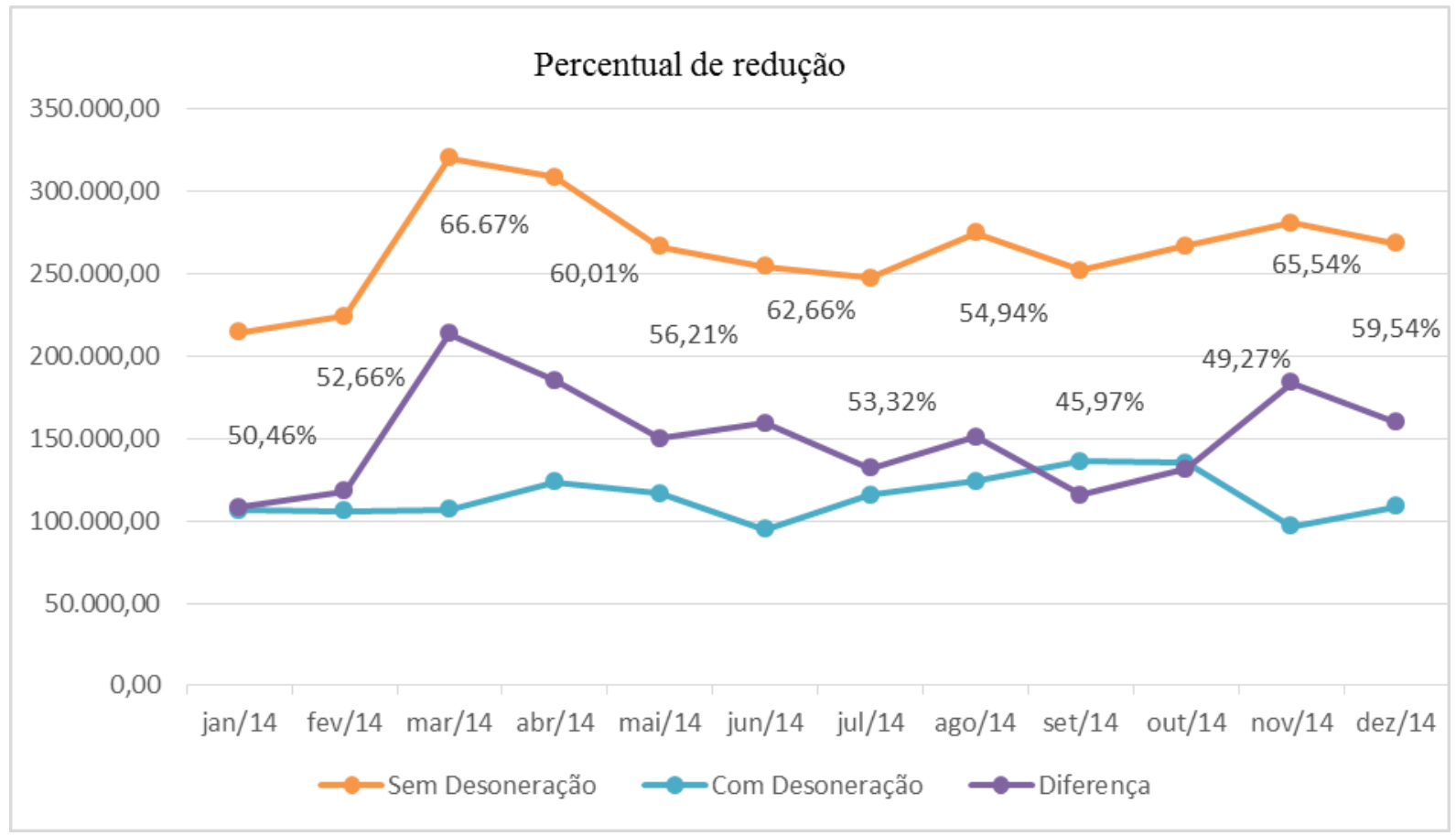

Fonte: Dados da pesquisa.

No Gráfico 1, apresenta-se os percentuais de redução que a empresa obteve, após a implantação do benefício concedido pelo Governo Federal através da lei 12.546/2011 (desoneração da folha), no mês de março de 2014 houve a maior economia, apresentando um percentual de $66,67 \%$ de diferença, a menor redução foi no mês de setembro apresentando um percentual de 45,97\%. Deste modo, foi possível observar que a empresa obteve redução da carga tributária trabalhista no ano de 2014, tendo um impacto financeiro bem favorável, neste caso é notável que os incentivos criados pelo Governo Federal, são otimistas para a empresa pesquisada. 
Conforme, o estudo de Nascimento e Juvella (2014) a desoneração da folha foi favorável, para determinada empresa pesquisada, que se percebe a redução do imposto pago, trazendo uma grande vantagem para a mesma. Mas, é importante frisar, que muitos administradores, empresários, autores de obras e partes dos governantes entendem que a desoneração da folha de pagamentos deveria ser uma opção e não uma obrigação, pois desta forma cada empresa poderia analisar qual a melhor forma de contribuição.

Corroborando, Mazzafero (2013), confirma que a desoneração fiscal é um assunto importante tanto para os segmentos industriais, comerciais, varejo, hoteleiro, entre outros, pois, é uma expectativa dos empresários, que buscam tornarem-se mais competitivos nos seus segmentos, ou seja, em garantir as vagas no mercado de trabalho desse setor. Portanto, para a empresa pesquisada a Contribuição Previdenciária foi favorável, possibilitando maior competitividade em seu seguimento de mercado.

\section{CONSIDERAÇÕES FINAIS}

Após analisar a indústria "Alfa" que atua no ramo alimentício no município de Tangará da Serra/MT, foi possível verificar a redução da carga tributária sobre a folha de pagamento, pois houve uma redução no INSS Patronal R $\$ 1.808 .001,41$ no ano de 2014 conforme apresentado na Tabela 4 . Vale ressaltar, que na comparação realizada na Tabela 4 entre o INSS patronal faturamento $\mathrm{X}$ desoneração da folha, foi possível constatar uma redução bastante significativa no ano estudado. Essa redução chegou a 56,89 \% de impacto financeiro satisfatório, ou seja, gerando uma diminuição considerável de INSS patronal a recolher no ano pesquisado.

Diante do exposto, o objetivo geral da pesquisa foi atingido, pois foi evidenciado nas tabelas 2, 3 e 4 o impacto financeiro ocasionado pela implantação da desoneração da folha de pagamento na indústria alimentícia pesquisada. Desta forma, pode-se concluir que o benefício concedido pelo Governo Federal foi benéfico para a mesma, pois como demonstrado na Tabela 3, é possível observar a redução expressiva do INSS patronal sobre a receita bruta, destacando a contribuição para as empresas beneficiadas pela Lei nº 12.546/2011.

Quanto aos objetivos específicos da pesquisa, todos foram atingidos, ou seja, foram conceituadas as legislações dando todo embasamento para o entendimento da desoneração da folha de pagamento. Quanto às vantagens e desvantagens da desoneração, foram demonstradas nas Tabelas 2, 3 e 4, ou seja, sendo benéfico para a empresa o enquadramento 
na nova sistemática de recolhimento do INSS Patronal, pois o valor que incide sobre a folha de pagamento reduziu em $50 \%$.

Vale ressaltar, que para a indústria alimentícia de Tangará da Serra, no que tange a desoneração da folha de Pagamento, a perspectiva é positiva. Quanto ao objetivo especifico levantado foi totalmente atingido, pois o pagamento do INSS pela desoneração da folha de pagamento, demonstrado na Tabela 4, teve uma economia financeira de $\mathrm{R} \$ 1$ 1.808.001,41. Desta forma, a indústria poderia realizar novos investimentos em treinamento dos funcionários, contratação de novos funcionários, compra de novos equipamentos, reformas na indústria, ampliação de infraestrutura entre outros investimentos necessários.

No entanto, a desoneração da folha de pagamento nem sempre será benéfico em seus resultados, pois é levando em consideração o faturamento das empresas (variável mensalmente), baixo custo mão de obra (variável pela demanda), ou vice-versa podem ser divergentes do resultado dessa pesquisa. Porém, a maneira de minimizar os prejuízos seria a opção facultativa por parte dessas empresas. Para isso é necessário fazer um estudo antes de optar pela implantação da desoneração da folha na entidade ou em qualquer outro ramo de atividade atribuídos pela Lei $n^{\circ} 12.546 / 2011$. Mas, para a indústria pesquisada, é notável a importância da implantação da desoneração da folha de pagamento.

Ao considerar o estudo e os resultados obtidos sugere-se, para pesquisas futuras, pesquisar outra atividade, como sugestão o setor de Hoteleiro, buscando conhecer as vantagens e desvantagens da desoneração da folha, demonstrado os impactos financeiros ocasionados pela implantação da desoneração da folha de pagamento com base na Lei $n^{\circ}$ 12.546/2011 no município de Tangará da Serra/MT.

\title{
IMPACT OF THE DELETION OF THE PAYMENT SHEET IN AN ANIMAL INDUSTRY
}

\begin{abstract}
This paper highlights the changes in business by the changes caused by the entry of Law No. 12,546 of December 14 of 2011, as regards the Contribution Social Security Replacement, popularly known as "Exemption of Payroll" treated in Articles $7^{\circ}$ and $8^{\circ}$. Given the above, the purpose is to reduce the tax burden on the payroll of the companies. The objective of the study was to present the financial impact caused by the implementation of payroll tax relief in a food industry Tangara da Serra - MT. The advantages and disadvantages of the new legislation were analyzed through monthly payroll data and annual revenues in 2014 collected in the company, making comparisons with previous rules. To achieve the objectives, the methodological procedures used these are case study of exploratory and quantitative approach, and for better understanding of the issue were addressed bibliographic research,
\end{abstract}


documentary and legislation. With the survey results, the calculation without exemption is reached on the cluster of $\mathrm{R} \$ 3.178 .213,73$, and with the exemption, that value has a significant reduction of $\mathrm{R} \$ 1.370 .212,32$, with a financial impact of $\mathrm{R} \$ 1.808 .001,41$ less to be collected in the period surveyed. So the payroll relief brought a positive financial impact, represented a savings of 56.89\% in the INSS Employer collecting in the year 2014.

Key words: Payroll. Social Security Contribution. Tax Burden.

\section{REFERÊNCIAS}

BRASIL. Constituição (1988). Constituição da República federativa do Brasil de 1988. Brasília, DF: Senado, 5 de outubro de 1988a. Disponível em <http://www.planalto.gov.br/ccivil_03/constituicao/ConstituicaoCompilado.htm>. Acesso em 09 de abr. 2015.

BRASIL. Constituição da República dos Estados Unidos do Brasil de 16 de julho de 1934b. Reunidos em Assembleia Nacional Constituinte para organizar um regime democrático, que assegure à Nação a unidade, a liberdade, a justiça e o bem-estar social e econômico e dá outras providencias. Disponível em:

<http://www.planalto.gov.br/ccivil_03/Constituicao/Constituicao34.htm>. Acesso em 14 de nov. de 2015.

BRASIL. Presidência da República. Casa Civil. Lei 8.212 de 24 de julho de 1991c. Dispõe sobre a organização da Seguridade social, institui o plano de custeio; e dá outras providencias. Disponível em:< http://www.planalto.gov.br/ccivil_03/leis/18212cons.htm>. Acesso em 09 de abr. 2015.

Lei 8.213 de 24 de julho de 1991d. Da Finalidade e dos Princípios Básicos da Previdência Social. Disponível em: <http://www.planalto.gov.br/ccivil_03/Leis/L8213cons.htm>. Acesso em 09 de abr. 2015.

Lei $\mathrm{n}^{0} 12.546$ de 14 de setembro de 2011e. Altera a alíquota das contribuições previdenciárias devidas pelas empresas que menciona o art. $7^{\circ}$ e $8^{\circ}$; e dá outra providencias. Disponível em: <http://www.planalto.gov.br/CCIVIL_03/_Ato20112014/2011/Lei/L12546.htm>. Acesso em 21 de fev. de 2015.

Lei $\mathbf{n}^{\circ}$ 12.715, de 17 de setembro de 2012f. Altera a alíquota das Contribuições Previdenciárias sobre a folha de salários devida pelas empresas que especifica; e dá outras providencias. Disponível em: <http://www.planalto.gov.br/ccivil_03/_Ato20112014/2012/Lei/L12715.htm>. Acesso em 21 de fev. 2015.

Lei $\mathbf{n}^{0}$ 12.794, de 02 de abril de 2013g. Altera a Lei no 12.546, de 14 de dezembro de 2011, quanto a Contribuição Previdenciária de Empresas dos Setores Industriais e de Serviços; e dá outras providencias. Disponível em: <http://www.planalto.gov.br/ccivil_03/_ato2011-2014/2013/lei/112794.htm>. Acesso em 23 de Ago. 2015. 
Lei $\mathrm{n}^{\circ} \mathbf{1 2 . 8 4 4}$, de 19 de julho de 2013h. Altera a Lei $\mathrm{n}^{\circ} 12.546$, de 14 de dezembro de 2011, para alterar o regime de desoneração da folha de pagamentos; art $50^{\circ}$ Inciso II. Anexo I e II e dá outras providências. Disponível em: <http://www.planalto.gov.br/ccivil_03/_ato2011-2014/2013/lei/112844.htm>. Acesso em 23 de Ago. 2015.

Decreto-Lei $\mathbf{n}^{0} 5.452$ de 01 de maio de 1943i. Aprova a Consolidações das Leis do Trabalho. Disponível em: 〈http://www.planalto.gov.br/ccivil_03/decreto-lei/del5452.htm〉. Acesso em 21 de fev, de 2015.

BRASIL. Ministério da Fazenda, 2012j. Desoneração da Folha de Pagamento, cartilha de perguntas e respostas. Disponível em:

<http://www1.fazenda.gov.br/portugues/documentos/2012/cartilhadesoneracao.pdf >. Acesso em 26 de abr. de 2015.

BRASIL. Medida Provisória $n^{0}$ 540, de 02 de agosto de 2011L. Altera a incidência das contribuições previdenciárias devidas pelas empresas que menciona, e dá outras providencias. Disponível em: <https://www.receita.fazenda.gov.br/legislacao/MPs/2011/mp540.htm>. Acesso em 23 de Ago. de 2015.

Medida Provisória n⿳0 669/2015m. Sumário Executivo de Medida Provisória Disponível em: <http://www12.senado.gov.br/publicacoes/estudos-legislativos/tipos-deestudos/sumarios-de-proposicoes/mpv669>. Acesso em 02 de mai. de 2015.

BRASIL. Decreto no 3.048, de 06 de maio de 1999n. Aprova o Regulamento da Previdência Social e dá outras Providencias. Disponível em:

<http://www.planalto.gov.br/ccivil_03/decreto/d3048.htm>. Acesso em 20 de nov. de 2015.

Decreto Legislativo no 3.724 - de 15 de janeiro de 1919o - DOU de 31/12/1919.

Regula as obrigações resultantes dos acidentes no trabalho e dá outras providencias.

Disponível em: <http://www010.dataprev.gov.br/sislex/paginas/23/1919/3724.htm>. Acesso em 14 de nov. de 2015.

BRASIL. DECRETO N 9.912-A, DE 26 DE MARÇO DE 1888P. REFORMA OS CORREIOS DO IMPÉRIO E DÁ OUTRAS PROVIDENCIAS. DISPONÍVEL EM: <HTTP://WWW2.CAMARA.LEG.BR/LEGIN/FED/DECRET/1824-1899/DECRETO-9912A-26-MARCO-1888-542383-PUBLICACAOORIGINAL-50955-PE.HTML>. ACESSO EM 14 DE NOV. DE 2015.

BEUREN, Maria Ilse et al. Como Elaborar Trabalhos Monográficos em Contabilidade: Teorias e Praticas. 2. ed. São Paulo: Atlas, 2004.

BERTINI, Emerson Rollof; WUNSCH, Paulo Eduardo Rosselli. O Impacto Financeiro e Contábil da Desoneração da Folha de Pagamento em Indústrias Calçadistas do Vale do Paranhana. Faculdade Integrada de Taquara, FACCAT, Taquara - RS, 2013.

BISCAIA, Diego Fernando et al. O estudo da Folha de Pagamento. Uma descrição dos proventos e descontos sob o âmbito legal e contábil. 2008. 85 f. Trabalho de conclusão de Curso (Graduação em Ciências Contábeis) - UNIFAE - Centro Universitário. Curitiba, 2008. 
COSTA, Rose Leide de Souza. PAIXÂO; Taisa Mara Santos da. AGUIAR; José Hilton Santos. Impactos da Desoneração da Folha de Pagamento em Empreendimentos do Munícipio de Salvador. Revista de Iniciação Cientifica - RIC Cairu. Jan 2015, Vol. 02, nº 01, p.179195, ISSN 2258- 1166.

ECKERT, Alex et al. Impacto da Desoneração da folha de Pagamento: Estudo de Caso em uma Metalúrgica fabricante de Autopeças. CONVIBRA, 2013.

FABRETTI, Láudio Camargo. Contabilidade tributaria. 4 ed. São Paulo: Atlas, 1998.

GOULART, Maria Madalena Córdova. Um estudo sobre a desoneração da folha de pagamento com base na Lei $\mathbf{n}^{\circ} \mathbf{1 2 . 5 4 6 / 2 0 1 1}$. 2012. Trabalho de Conclusão de Curso de Ciências Contábeis. Universidade de Extremo Sul Catarinense. UNESC. Criciúma, SC.

HOMCI, Arthur Laércio. A evolução histórica da previdência social no Brasil. Revista JusNavigandi, Teresina, ano 14, n. 2104, 5 abr. 2009. Disponível em:

<http://jus.com.br/artigos/12493>. Acesso em 13 de mai. de 2015.

MAZZAFERO, Tiago Felipe do Prado. O Impacto da Desoneração da Folha de Pagamento no Segmento Industrial no Município de Capivari/SP. Projeto de Pesquisa de Monografia de Conclusão de Curso. Curso de Graduação em Ciências Contábeis. Faculdade de Cinecista de Capivari - CNEC. 40 pag. 2013.

MENDONÇA, Alex Assis de. MOURA, Emerson Affonso da Costa. Política pública de fomento, desoneração Tributária e Contribuição Previdenciária incidente sobre a Folha de Pagamento. Revista do Direito Público. Londrina, v.9, n.3, p.153-177, set./dez.2014. DOI: 10.5433/1980-511X.2014v9n3p153.

MODENA, Anize et al. Desoneração da Folha Pagamento em um estabelecimento varejista de Caxias do Sul/RS. Anais VII Seminários de Iniciação Cientifica Curso de Ciências Contábeis da FSG. V.4, N.2 (2013) - ISSN 2237-8472.

NASCIMENTO, Elisangela Lindalva do; JUVELLA, Solange Benites. Impactos da Desoneração da folha de Pagamentos no setor de Construção Civil. Anais do III SINGEP e II S2IS - São Paulo/SP - Brasil - 09, 10 e 11/11/2014.

KINCZESKI, Gabriel Nascimento. Folha de pagamento: impacto financeiro dos gastos com empregados gerados pela política de expansão de uma empresa. Monografia do Curso de Ciências Contábeis. Universidade Federal de Santa Catarina, Florianópolis, 2011.

OLIVEIRA, Luiz Martins de; CHIEREGATO, Renato; JUNIOR, José Hernandez Perez; GOMES, Marliete Bezerra. Manual de Contabilidade Tributaria. $2^{\circ}$ ed. São Paulo: Atlas, 2003.

PELLEGRINI, Josué; MENDES, Marcos. O que é desoneração da folha de pagamento e quais seus possíveis efeitos? 11 de ago. 2014. Disponível em: <http://www.brasil-economiagoverno.org.br/2014/08/11/o-que-e-desoneracao-da-folha-de-pagamento-e-quais-sao-seuspossiveis-efeitos/>. Acesso em 12 de mai. de 2015. 
PINTO, Vilma da Conceição; AFONSO, Jose Roberto; BARROS, Gabriel Leal de. Avaliação Setorial da Desoneração da Folha de Salários. Nota Técnica. FGV/IBRE, 2014.

RICHARDSON, Roberto Jarry et al. Pesquisa Social Métodos e Técnicas. $3^{\mathrm{a}}$ ed. Rev. Ampliada. São Paulo, 2012.

SILVA, Aline Santos. A Desoneração da folha de Pagamento: Estudo de caso na empresa Metalúrgica Aço e Silva - LTDA. Graduanda em Ciências Contábeis - Cesuca, 2014.

TEODORO, Felipe Matias. Um estudo Sobre a Desoneração da Folha de Pagamento: Contribuição Previdenciária sobre a Receita Bruta. Trabalho de conclusão de curso em Ciências Contábeis, UNESC, 2014.

VANDERBECK, Edward J. NAGY, Charles F. Contabilidade de Custos. 11 ed. São Paulo: Pioneira Thomson Learning, 2001.

YIN, Robert, k. Estudo de Caso. Planejamento e Métodos. 4 ed. Porto Alegre: Bookman, 2010. 